\title{
Cultura constitucional Constitutional culture
}

\author{
Mariano C. Melero De la Torre \\ Universidad Autónoma de Madrid \\ mariano.melero@uam.es
}

Recibido / received: 30/07/2018

Aceptado / accepted: 02/08/2018

DOI: https://doi.org/10.20318/eunomia.2018.4352

\section{Resumen}

La "cultura constitucional" hace referencia a la Constitución "realizada" o "actualizada" en las prácticas, hábitos y actitudes de los poderes públicos y la ciudadanía en general de una comunidad política. Este artículo trata de explorar las formas de interdependencia de la norma constitucional y la realidad cultural, añadiendo al final algunas reflexiones sobre el papel de los jueces en un Estado constitucional.

\section{Palabras clave}

Cultura constitucional, mutación constitucional, cultura de la autoridad, cultura de la justificación, cultura democrática de la justificación.

\begin{abstract}
The "constitutional culture" means the "realization" or "actualization" of the Constitution in the practices, habits and attitudes of the public powers and the general citizenship of a political community. This paper tries to explore the forms of interdependence between the constitutional norm and the cultural reality, adding at the end some reflections about the role of judges in a constitutional State.
\end{abstract}

\section{Keywords}

Constitutional culture, living tree, culture of authority, culture of justification, democratic culture of justification.

SUMARIO. 1. Introducción. 2. La interdependencia de la Constitución y la realidad cultural. 3. El papel de los jueces en un Estado constitucional.

\section{Introducción}

La voz "cultura constitucional" hace referencia a una realidad compuesta de dos elementos en persistente e inevitable tensión: la norma jurídica y la realidad social, el Derecho constitucional y las prácticas, hábitos y actitudes de una comunidad política. La cultura constitucional hace referencia a la Constitución como cultura, es decir, 
como el conjunto de prácticas políticas, jurídicas y sociales en que se "realizan" o "concretan" los requerimientos de la Constitución en la sociedad a la que van dirigidos.

Debido a la tensión entre ambos elementos (norma y realidad), la Constitución nunca llega a realizarse del todo, y se requiere mucho tiempo para ver surgir a partir de una Constitución positiva una cultura constitucional razonablemente "realizada". Pero lo cierto es que una Constitución sin cultura constitucional no es más que "letra muerta", un documento anacrónico que nada tiene que ver con el régimen político efectivamente existente, o, en el peor de los casos, una "constitución camuflaje" que pretende ocultar el funcionamiento real de un régimen autoritario. Aunque todo régimen político descansa en alguna clase de constitución, la diferencia entre un régimen democrático y un régimen autoritario radica en que este último puede ser perfectamente efectivo sin una cultura constitucional. Un régimen autoritario se caracteriza por "una tremenda distancia entre la constitución formal y la constitución real" (Lane, 1996: 119, énfasis añadido). Una Constitución democrática, en cambio, no puede existir sin que sus preceptos estén "vivos" en la forma de actuación de los poderes públicos y en las ideas, experiencias y valores de la comunidad política.

Es en este sentido que se habla de "cultura constitucional", es decir, la clase de cultura política y jurídica existente en un Estado constitucional democrático, en cuyo seno la distinción entre Estado y sociedad pierde todo significado relevante para la teoría de la Constitución (Hesse, 2011: 122-124). La simbiosis del Estado y la sociedad en la cultura constitucional no se produce, como ocurre en los regímenes totalitarios o militarizados, por un proceso de estatalización de la sociedad, sino a la inversa, a través de la socialización del Estado. Mientras que en el siglo XIX, el Estado liberal se "corporeizaba" en el Ejecutivo monárquico, desde la segunda mitad del XX el Estado constitucional es un producto social que toma cuerpo exclusivamente en el espacio de la cooperación social, como una parte de la actuación social del ser humano. En el Estado democrático y social (también llamado Estado del Bienestar), los poderes públicos son un componente decisivo en la formación y conformación de la vida social (mediante las medidas de planificación y asistencia social); simultáneamente, los principios y valores que guían la actuación de los poderes públicos son los compromisos morales últimos de la sociedad. La discusión fundamental en el Estado constitucional moderno es precisamente qué tareas de planificación y asistencia previstas en la Constitución no se deberían asumir por el Estado.

\section{La interdependencia de la Constitución y la realidad cultural}

La Constitución jurídica, o el Derecho constitucional democrático, depende de la realidad cultural en un doble sentido. Por una parte, la fuerza normativa de la Constitución depende de la "posibilidad de realización" de sus contenidos, es decir, de que tales contenidos estén conectados o den respuesta a las circunstancias de la situación histórico-concreta, es decir, el estado de desarrollo espiritual, social, político o económico de su tiempo. Para ello, el constitucionalismo emplea la estrategia de la abstracción: como señala Konrad Hesse, el contenido constitucional debe estar "abierto al tiempo" (Hesse, 2011: 46), con cláusulas indeterminadas que puedan adaptarse al cambio incesante de las circunstancias históricas. Si la Constitución pretende normar la vida social con demasiado detalle, su vigencia solo se podrá garantizar a costa de una continua reforma constitucional, con el consiguiente deterioro de su fuerza normativa suprema.

Por otra parte, la vigencia efectiva de la Constitución requiere de la "voluntad constante de los implicados en el proceso constitucional de realizar" los mandatos constitucionales -lo que Hesse denomina la "voluntad de Constitución" (Hesse, 2011: 
53). La realización o actualización de la Constitución depende, como la mayoría de las normas jurídicas, de la actuación humana. En general, la norma efectiva o vigente es aquella que motiva y determina la conducta humana. Sin embargo, los poderes públicos no pueden garantizar la actualización de la Constitución en la misma medida en que garantizan el resto del sistema jurídico, puesto que la actuación de los poderes públicos presupone ya una Constitución en vigor. En el Estado constitucional, no hay autoridad sin derecho. Según señala Hesse, se confunde la naturaleza y la función del "proceso" o "poder constituyente" cuando se lo concibe como un único acto de voluntad "originario" del que derivan todos los poderes constituidos así como la obligatoriedad misma de los requerimientos constitucionales. En realidad, la vigencia real de la Constitución "es cuestión de fuerza normativa, de su capacidad de operar en la realidad de la vida histórica de forma determinante y reguladora" (ibíd., 52). Por eso, más que en cualquier otra área del derecho, el derecho constitucional no puede ser desvinculado de la actuación humana. La unidad política del Estado y el mantenimiento del orden jurídico dependen de que la Constitución sea una norma "de letra viva", o mejor, un "orden vivido, formador y conformador de realidad histórica" (ibíd.: 51).

Esta interdependencia de la Constitución jurídica y la realidad cultural es la idea que está detrás de la metáfora anglosajona de la Constitución como un "living tree", y es la que fundamenta lo que en la doctrina alemana se conoce como la "mutación constitucional" a través de la interpretación. La idea es básicamente que la concreción y realización de la norma constitucional se produce mediante una interpretación "dinámica" o "constructiva" de su texto. Mediante este tipo de interpretación, los resultados de la "concreción" de la norma constitucional pueden variar según los cambios que acontezcan en su "ámbito normativo", sin tener que modificar el texto de la norma ni los elementos esenciales de su "programa normativo". En el Estado constitucional, dicha interpretación corresponde potencialmente a todos los poderes públicos y la ciudadanía. La Constitución no puede llegar a ser una realidad cultural si los procesos de la interpretación constitucional no se realizan dentro de lo que Peter Häberle ha denominado una "sociedad abierta de los intérpretes constitucionales". Para Häberle (2007: 194), el autor que más pormenorizadamente ha desarrollado el concepto de "cultura constitucional", este tipo de cultura política y jurídica es "la expresión de un estado de desarrollo cultural, un medio de autorrepresentación de un pueblo, un espejo de su herencia cultural y fundamento de sus nuevas esperanzas". La cultura constitucional es, pues, una Constitución de "cuño cultural".

No obstante, la mutación constitucional a través de la interpretación tiene solo unas posibilidades limitadas. En primer lugar, por consideraciones democráticas que tienen que ver con la Constitución como precompromiso (Elster, 1984), en un Estado democrático de derecho cada generación debe estimar la Constitución como suya, no como el compromiso heredado de las generaciones pretéritas, por lo que la reforma constitucional debe considerarse como un proceso normal en el desarrollo existencial de una Constitución (Rubio Llorente, 2012: 132). Además, como señala Hesse, cuando a través de la interpretación se llega a unos contenidos que contradicen el texto de la norma (y con ello su "programa normativo"), no cabe considerar tales contenidos como "realidad constitucional". No puede haber una realidad constitucional en contra del Derecho constitucional, puesto que estaría otorgándose a esa realidad inconstitucional una fuerza normativa superior a la fuerza normativa de la Constitución y del Derecho. Frente a una realidad inconstitucional incapaz de producir ninguna interpretación conforme a la Constitución vigente, solo es posible salvar la vigencia de la Constitución mediante dos opciones: o bien recurrir a una política constitucional dirigida a crear las condiciones para su realización legítima, o bien reformar la Constitución (Hesse, 2011: 55). 


\section{El papel de los jueces en un Estado constitucional}

Por último, quisiera terminar con una de las cuestiones más controvertidas en el debate contemporáneo de teoría constitucional: ¿cuál debería ser el papel de los jueces (especialmente de los jueces constitucionales) en esa "sociedad abierta de intérpretes constitucionales"? A mi modo de ver, los jueces tienen y deben tener un papel decisivo en un Estado constitucional, aunque este papel no siempre se estime lo suficiente debido al "déficit democrático" que suele asociarse al control jurisdiccional de constitucionalidad de las leyes. En mi opinión, la importancia de dicho control radica en que con ello se asegura el carácter justificativo de la Constitución y del sistema jurídico. En efecto, la cultura constitucional es una "cultura de la justificación" en la medida en que incorpora unos jueces (o cualesquiera otros funcionarios independientes) con autoridad suficiente para garantizar (en última instancia) a los ciudadanos que aquellas decisiones del legislador y de los poderes públicos que afectan a sus derechos están razonablemente bien fundadas en los principios constitucionales. Lo que no significa, como hemos dicho, que sean los jueces los únicos capaces de concretar o definir el alcance de tales principios en cada caso, ni que sean los tribunales los únicos encargados de garantizar la compatibilidad de las leyes y decisiones públicas con los derechos protegidos.

Como dijimos al inicio, toda sociedad democrática consolidada tiene una cultura constitucional sobre la que se asientan sus instituciones y normas jurídicas. Ahora bien, la cultura constitucional puede ser una "cultura de la autoridad" o una "cultura de la justificación". Esta contraposición de culturas constitucionales fue utilizada por el jurista sudafricano Etienne Mureinik en el contexto de la transición democrática de su país. Según Mureinik, la base jurídica de una cultura de la autoridad reside en la doctrina de la soberanía parlamentaria. "Universalmente, esa doctrina enseña que lo que dice el Parlamento es ley, sin necesidad de ofrecer ninguna justificación a los tribunales". Por el contrario, en una cultura de la justificación, "el liderazgo del gobierno descansa en la contundencia de los argumentos que ofrece en defensa de sus decisiones, no en el miedo que inspira la fuerza de sus órdenes" (Mureinik, 1994: 31, 32). Una cultura constitucional de la justificación es aquella que está basada en la persuasión y no en la coerción; una cultura en la que es costumbre que todo ejercicio del poder se justifique apelando a razones públicamente disponibles cuya compatibilidad con los valores constitucionales se garantiza mediante una supervisión independiente. En este sentido, creo que el control de constitucionalidad no es contrario o no debilita el autogobierno democrático, sino al contrario, sirve para garantizar su integridad al obligar a los poderes públicos a justificar sus decisiones conforme a los compromisos morales últimos de una sociedad democrática.

En la práctica constitucional contemporánea, cabe distinguir tres clases de culturas de la justificación:

- La cultura de la justificación en el modelo "americano": En la teoría constitucional se suele considerar este modelo como el "clear-cut example" de la supremacía judicial, y por tanto como una instancia de "cultura de la autoridad", donde la "soberanía" no pertenece a los legisladores ( $\mathrm{y}$, por tanto, al pueblo) sino a la judicatura ( $y$, como titulares del derecho a la tutela judicial efectiva, a los individuos aisladamente considerados) (Cohen-Eliya y Porat, 2011). Sin embargo, una corriente importante de la teoría constitucional norteamericana describe el trabajo del Tribunal Supremo de los EEUU como una conversación constitucional de larga data con el pueblo (en este sentido, cabe mencionar, entre otros, a Alexander Bickel, Louis Fisher y Barry Friedman). 
- La cultura de la justificación en el modelo "europeo": En el constitucionalismo europeo de posguerra, con Constituciones escritas, rígidas y "rematerializadas" (con una pluralidad de valores y principios morales sustantivos), no se produce el mismo "déficit democrático" que en el anterior, puesto que en este modelo el control jurisdiccional de constitucionalidad se concentra en un único tribunal relativamente independiente de los demás poderes del Estado, incluido el poder judicial. Sin embargo, creo que el monopolio de dicho tribunal en materia de interpretación constitucional no puede dejar de deteriorar la deliberación democrática sobre los derechos. A pesar de ello, tampoco faltan lecturas de este modelo desde una clave deliberativa, donde los Tribunales Constitucionales son vistos como un recurso más efectivo que los tribunales ordinarios de justicia (incluido el Supremo) para dinamizar una cultura de la justificación incluso en organizaciones políticas supraestatales (Ferreres, 2011). En este sentido, se suele resaltar el papel de los Tribunales Constitucionales europeos en el proceso de formación del Derecho constitucional común europeo (Häberle, 2007: 161-175).

- La cultura de la justificación en el modelo "commonwealth" (Reino Unido, Canadá y Nueva Zelanda): En esta tradición siempre ha existido una "constitución no escrita" (no recogida en un documento canónico) que los jueces se han encargado de deducir y desarrollar a través de la judicial review. Hasta la segunda mitad del siglo XX (la llamada "revolución de los derechos"), el control judicial en los sistemas common law se reducía a la supervisión de la legalidad de los actos administrativos. A partir de los años sesenta (con la pionera Bill of Rights canadiense de 1960) se producen en este contexto una serie de desarrollos constitucionales con una misma finalidad: reforzar el papel de los poderes políticos representativos en la determinación concreta de los derechos humanos, introduciendo de algún modo la posibilidad efectiva para que dichos poderes respondan y contradigan las determinaciones judiciales. Por este motivo, se ha llamado a este tipo de cultura constitucional, "una cultura democrática de la justificación" (Dyzenhaus, 2015; Hunt, 2015).

A mi juicio, la cultura constitucional debe tender a ser lo más posible una cultura democrática de la justificación. La supremacía judicial va en contra del principio básico de la "autonomía democrática": las personas que toman decisiones sobre cómo gobernarnos deben ser elegidas y deben responder ante su electorado. Lo cual no significa tener que asumir una concepción de la autoridad según la cual las consideraciones democráticas operan como "razones de segundo orden" que nos imponen la mera sumisión a las decisiones del legislativo/ejecutivo. Aun así, en una cultura constitucional donde la autoridad deriva principalmente de la calidad de las razones, es preciso, para evitar el riesgo de la supremacía judicial, otorgar algún peso al pedigrí democrático del agente decisor, al grado de participación que hayan tenido los individuos afectados en el proceso que condujo a la decisión, así como a la disponibilidad y efectividad de otras formas de rendición de cuentas. Reconocer que tales consideraciones democráticas deben tener un peso sustantivo no significa, sin embargo, que deban asumirse como razones concluyentes. El objetivo de una "doctrina de la deferencia judicial debida" (es decir, de la autorrestricción de los jueces constitucionales) es tratar de responder precisamente a la difícil cuestión de cuál es el papel que han de jugar tales consideraciones (fundamentalmente, la competencia institucional relativa y la legitimidad democrática) en el control judicial de las decisiones públicas.

La obligación de la autoridad pública de dar razones de sus decisiones es una parte esencial de una cultura de la justificación. Por ello, esta justificación debe tener como principal propósito facilitar a los jueces la base para un "control procesal" (o cuasi-procedimental) en el que se evalúa en qué medida la decisión adoptada se sigue de las razones ofrecidas, de tal modo que dichas razones pasan a ser con 
frecuencia el elemento decisivo para determinar la legalidad de la decisión. Es cierto que, al revisar la adecuación de las razones, los jueces pueden sentirse tentados de valorar la corrección o los "méritos" de la decisión misma. Sin embargo, como ha señalado Michael Taggart (2008: 463), respaldar las decisiones con explicaciones racionales es "el primer paso de la deferencia como respeto" y una importante barrera contra la determinación inapropiada por parte de los jueces de la intensidad que requiere la supervisión de cada caso. En una cultura de la justificación, las razones ofrecidas por el agente decisor principal (legislativo/ejecutivo) deben considerarse como el punto de partida de la evaluación del juez respecto a cuál ha de ser la intensidad de su escrutinio o, lo que es lo mismo, la deferencia que debe mostrar hacia el agente decisor principal.

Cuando los tribunales insisten en que las decisiones han de tomarse del modo correcto, contribuyen a mejorar el nivel de la toma de decisiones de las autoridades públicas, "introduciendo más firmemente la cultura de los derechos humanos en el proceso público de toma de decisiones" (Beatson et al., 2008: 235). Esta idea tiende a provocar una gran oposición porque supone despojar a los jueces del monopolio de las respuestas correctas cuando las cuestiones tratan sobre derechos fundamentales. Sin embargo, como hemos visto, una cultura constitucional promueve que todos los poderes del Estado participen como socios en el proceso de articulación de tales derechos (es decir, en la determinación de cómo deben interpretarse y aplicarse). Un control judicial basado en el proceso de toma de decisiones, al no estar centrado en el contenido de la decisión, promueve una mayor legitimidad de la intervención de los tribunales en el proceso de toma de decisiones públicas ${ }^{1}$. Esta forma de entender el control judicial armoniza mejor con el tipo de deferencia que los tribunales deben mostrar hacia quienes tienen la responsabilidad principal en la toma de decisiones, una posición que a menudo se justifica diciendo que los tribunales no están muchas veces en la mejor situación para valorar la proporcionalidad de las medidas impugnadas en cada caso (Beatson et al., 2008: 235). Si la impugnación ante la justicia tiene éxito, la decisión debe tomarse de nuevo sobre una base adecuada por el órgano responsable. Como afirma David Dyzenhaus (2014: 255), el cambio a una cultura de la justificación, lejos de dar más poder a los jueces, da más poder al Estado administrativo o regulador. En este tipo de cultura política y jurídica, las decisiones de los poderes públicos superan el control judicial en la medida en que tales poderes demuestran que sus decisiones son "justificables", aunque su contenido no coincida con las conclusiones que los jueces consideran correctas con independencia de las razones aportadas. En este sentido, la cultura de la justificación delinea y refuerza la separación de poderes, exigiendo al legislativo/ejecutivo que justifique el ejercicio de su poder, y requiriendo a los tribunales supervisores que defieran a la justificación razonable.

\footnotetext{
${ }^{1}$ Un control procesal "permite a los tribunales evaluar la racionalidad de la acción gubernamental, al tiempo que les exime de realizar la ponderación sustantiva de intereses. En su lugar, el tribunal verifica si el legislador ha basado su decisión en una ponderación sólida y amplia de intereses, o si estaban presentes las condiciones para su ejercicio. Lo cual no impone sobre el gobierno el deber de seguir un proceso bien definido, sino que meramente requiere unas garantías mínimas de una toma de decisiones ponderada y basada en evidencias", Popelier (2013: 252 ). El control judicial "es menos objetable cuando los tribunales sirven meramente como un árbitro externo e independiente que asegura que se cumplen las reglas del juego, en lugar de participar en el juego mismo dictando sus resultados", Bar-Siman-Tov (2011: 1971).
} 
Bibliografía

BAR-SIMAN-TOV, I. (2011), "The Puzzling Resistence to Judicial Review of the Legislative Process", Boston University Law Review, 91(6), pp. 1915-1974.

BEATSON, J. et al. (2008), Human Rights: Judicial Protection in the United Kingdom. London, Sweet \& Maxwell.

COHEN-ELIYA, M. y PORAT, I. (2011), "Proportionality and the Culture of Justification", The American Journal of Comparative Law, 59, pp. 463-490.

DYZENHAUS, D. (2014), "Proportionality and Deference in a Culture of Justification". En: Huscroft, G. et al. (eds.), Proportionality and the Rule of Law. Rights, Justification and Reasoning, Cambridge, Cambridge University Press, pp. 234-258.

DYZENHAUS, D. (2015), "What is a Democratic Culture of Justification?". En: Hunt, M. et al. (eds.), Parliament and Human Rights. Redressing the Democratic Deficit, Oxford, Hart, pp. 425-445.

ELSTER, J. (1984), Ulysses and the Sirens: Studies in Rationality and Irrationality, CUP, Cambridge.

FERRERES, V. (2011), Una defensa del modelo europeo de control de constitucionalidad, Marcial Pons, Madrid.

HÄBERLE, P. (2007), El Estado constitucional (trad. esp., H. Fix-Fierro), Astrea, Buenos Aires.

HESSE, K. (2011), Escritos de Derecho Constitucional (trad. esp., P. Cruz Villalón y M. Azpitarte Sánchez), CEPC, Madrid.

HUNT, M. (2015), "Introduction". En: M. Hunt, H. J. Hooper y P. Yowell (eds.), Parliament and Human Rights. Redressing the Democratic Deficit, Oxford, Hart, pp. 1-25.

LANE, J. E. (1996), Constitutions and Political Theory, Manchester University Press, Manchester.

MUREINIK, E. (1994), "A Bridge to Where?: Introducing the Interim Bill of Rights", South African Journal on Human Rights, 10, pp. 31-48.

POPELIER, P. (2013), "The Court as Regulatory Watchdog. The procedural approach in the case law of the European Court of Human Rights". En: P. Popelier, A. Mazmanyan y W. Vandenbruwaene (eds.), The Role of Constitucional Courts in Multilevel Governance, Cambridge, Intersentia, pp. 249-267.

RUBIO LLORENTE, F. (2012), La forma del poder. Estudios sobre la Constitución, Centro de Estudios Políticos y Constitucionales, Madrid.

TAGGART, M. (2008), "Proportionality, Deference, Wednesbury", New Zealand Law Review, pp. 423-481. 